Eduardo Silva, S.J.

Profesor de la Facultad de Teología de la Pontificia Universidad Católica de Chile y de la Universidad Alberto Hurtado

Jorge Costadoat, S.J.

Profesor de la Facultad de Teología de la Pontificia Universidad Católica de Chile

\title{
Centro Teológico Manuel Larraín: Una interpretación teológica del presente
}

\begin{abstract}
Este texto hace las veces de "carta de navegación" del Centro Teológico Manuel Larraín. Ha sido escrito para iluminar la actividad del centro y, al mismo tiempo, es producto de la discusión de sus miembros. Este documento quiere ser teología de una acción que, en este caso, ha consistido fundamentalmente en una conversación libre, informada y multidisciplinar entre hombres y mujeres de fe.
\end{abstract}

La teología en su esfuerzo por dar razón de la fe, ha de mediar los datos de la fe con la vida actual de los creyentes. Esta tarea de correlacionar el mensaje cristiano con la vida real tal como se va dando, de articular la experiencia cristiana fundamental con la experiencia de hoy, conlleva el doble trabajo de interpretar el presente a la luz de la fe y de interpretar el Evangelio y la Escritura desde la situación presente.

Tarea de todos los tiempos que el Concilio Vaticano II, al considerar la naturaleza y misión de la Iglesia en el mundo contemporáneo, lleva a cabo con un discernimiento y una interpretación de la situación histórica en la que la Iglesia está inmersa y de la que forma parte. Esta operación, que da su contenido y método a Gaudium et Spes, consiste en "escrutar los signos de los tiempos e interpretarlos a la luz del Evangelio" (GS, 4.). De esta manera la Iglesia conciliar ha querido hacer suyos y responder con la actualidad del mensaje del Evangelio a "los gozos y las esperanzas, las tristezas y las angustias de los hombres de nuestro tiempo, sobre todo de los pobres y de cuantos sufren" (GS, 1).

En nuestro continente tanto el magisterio como la teología latinoamericana asumen la perspectiva propugnada por el Concilio. Desde la conferencia episcopal de Medellín se da testimonio de una práctica episcopal y teológica en la que se intenta discernir con mirada pastoral la realidad de América Latina, y orientar los esfuerzos hacia una transformación que permita la liberación de los pobres y la evangelización de la cultura. 
La interpretación teológica de la época se nutre de la teología académica, del recurso que esta hace a varias otras disciplinas humanistas y científicas, y a la sabiduría creyente de pastores y laicos. La interpretación teológica del presente, en consecuencia, además de una historia tiene una actualidad particular. Su objetivo es discernir los signos de la actuación presente de Dios en vista a sugerir las acciones humanas que con mayor seguridad debieran verificarla.

El Centro Teológico Manuel Larraín intenta favorecer y desarrollar este discernimiento teológico de los signos de la acción de Dios en nuestro contexto histórico. Sabe, por tanto, que su perspectiva es limitada en el tiempo y espacio a este país latinoamericano llamado Chile y a un grupo de personas que mayoritariamente se desempeñan como académicos o son universitarios en general. La confesión de esta parcialidad tiene por objeto precisamente expresar la necesidad de una apertura, un contacto y un diálogo con una humanidad muchísimo más amplia y con la Iglesia universal.

Hasta ahora hemos querido abordar cuatro de estos signos de los tiempos y lo hemos hecho mediante la creación de cuatro equipos. Estos llevan el nombre del signo/tema que los convoca.

\section{CUATRO EQUIPOS MULTIDISPLINARES}

El grupo denominado Católicos en democracia se hace cargo del desafío que representa para la Iglesia el desenvolvimiento de los católicos en una sociedad democrática. Este desafío suscita preguntas sobre estructuras eclesiales que permitan y hagan posible una verdadera ciudadanía laical; un modo de colaboración de pastores y laicos en vista al bien común; un tipo de relación de la Iglesia con la sociedad que, por ser hoy pluralista, obliga a inventar un cristianismo sin cristiandad.

El tema de La virtud incluyente e integradora del Evangelio nos plantea preguntas sobre la inclusión social y eclesial de los "diversos" (familias monoparentales, convivientes, separados y divorciados, homosexuales, y todos los que no corresponden a un tipo ideal); y preguntas sobre nuestro actual modelo de desarrollo (pues, no obstante los avances notables en el plano de la reducción de la pobreza, la inequidad en Chile es enorme). A la luz de la fe, la globalización merece una atención especial porque así como bota fronteras y unifica, también genera desigualdad, exclusión y segregación.

Las metamorfosis de la religiosidad, el tercer tema, apunta a los cambios en la religión y a las nuevas modalidades de la experiencia religiosa. Se advierten tendencias comunes a la experiencia religiosa como son la privatización y la fragmentación en una variedad de posibilidades. Estas tendencias afectan al cristianismo y al catolicismo en particular, importan una crisis y levantan la pregunta por la reconfiguración histórica de la fe cristiana.

Con el cuarto tema se pretende recoger el legado de nuestra historia eclesial chilena y latinoaméricana, haciendo Memoria de la inculturación del Evangelio. La indagación en nuestra historia, desde la primera evangelización del continente, tiene por objeto último facilitar el escrutinio de los signos de los tiempos actuales que la 
Iglesia latinoamericana realizó desde Medellín, bajo el estímulo del Concilio Vaticano II y gracias al tesón de hombres como don Manuel Larraín.

\section{EL SENTIDO TEOLÓGICO DE LA REALIDAD}

Estos cuatro temas no son simplemente, para la mirada creyente, fenómenos humanos, transformaciones culturales, desafíos seculares, que es conveniente que ella comprenda para adaptar mejor el Evangelio que tiene que anunciar en este nuevo contexto (pluralista, lleno de exclusiones y de cambios religiosos y eclesiales). Estos cuatro temas -como otros signos de nuestro tiempo- no aluden a realidades externas al mensaje cristiano, como si ellas estuvieran allí enfrente a la espera del sentido que pueda otorgarles la evangelización. Estos signos de los tiempos son ya portadores de sentido, pues es Dios su autor. El Creador es quien, al actuar personal e históricamente en Jesucristo, nos prohíbe buscarlo en lugares sagrados, como si no se encontrara en otros que solemos llamar profanos. El Creador del mundo es también el Señor de la historia. El mismo Padre de Jesús que reconocemos presente en su Iglesia y en los sacramentos, nos mueve a reconocer en las acciones de los demás seres humanos su propia actuación secreta e infalible. La tarea de la teología es precisamente descubrir ese sentido en los hechos cotidianos e históricos. Interpretar teológicamente la realidad, descubrir la significación teológica de los acontecimientos, discernir los signos de los tiempos, interpretar la praxis a la luz del Evangelio son distintos modos de decir que la realidad, toda realidad, cualquier realidad humana, es portadora de sentido divino, que tiene sentido en el camino del hombre y la mujer hacia Dios.

A la teología corresponde desentrañar ese sentido "entre" otros sentidos y "en" los otros sentidos que la misma realidad tiene. La vida e historia humanas tienen muchos aspectos. La significación teológica de la realidad no acaba con la significación económica, política, psicoanalítica, estética, histórica y ética de la misma realidad. Todos estos sentidos son relevantes para la comprensión teológica. Las disciplinas que se ocupan de desentrañar estas variadas significaciones de la realidad son condición de posibilidad para que el teólogo comprenda mejor aquello que intenta discernir teológicamente, aunque no condición suficiente. La comprensión teológica de la realidad requiere de una multiplicidad de miradas. Las miradas que las disciplinas científicas ofrecen ayudan al teólogo a desentrañar el sentido creatural de la realidad, aunque ninguna de ellas por separado o conjuntamente puedan dar cuenta de la visión correspondiente a la teología. No hay comprensión verdaderamente teológica solo después o independientemente de las explicaciones de las otras disciplinas, a modo de lectura yuxtapuesta o alternativa de la realidad. Sin restar méritos a la senda abierta por el Concilio, ya "no basta con la yuxtaposición entre los momentos empírico y teológico de Gaudium et Spes: una amalgama de 'datos' cualitativamente diversos que como tales permanecen sin mediar" (1). Pero, por otra parte, la densidad de la realidad es tal que la mirada de estas otras disciplinas queda

(1) Juan Noemi, "La contemporaneidad de la teología. El ejemplo de Paul Tillich", Teología y Vida 17 (1976) 96-97. 
corta para captar su ulterior profundidad. Una teología auténtica debiera evitar dos cosas: primero, intentar construir un sistema de la doctrina cristiana pura, separada de los conocimientos culturales de la época, y, segundo, claudicar ante las ciencias como si el mensaje cristiano pudiera reducirse simplemente a las conclusiones científicas y culturales, sin poder ofrecer a ellas corrección y orientación alguna.

\section{LA VOCACIÓN TEOLÓGICA DE TODOS LOS BAUTIZADOS}

La teología necesita de otras ciencias para comprender la realidad, pero tampoco es obra exclusiva de especialistas. La teología es tarea de todos. No está reservada a ningún grupo particular de creyentes, por determinante que sea su contribución. La teología es, en primer lugar, interpretación teológica de la propia vida, pues en virtud de su bautismo cada cristiano debe estar dispuesto ante sí y ante los otros a dar razón de su esperanza $(1 \mathrm{Pe} 3,15)$. Su vida de fe no le exime del uso de su razón. La fe no es irracional. De la comprensibilidad que la razón otorga a la fe, depende el sentido que la vida del cristiano tiene para él y para los demás.

Por esto la interpretación teológica del presente se alimenta de la teología académica, amén de la reflexión personal sobre la propia vida de fe. Esta requiere de clarificaciones mayores, especializadas. Y, por otra parte, necesita también de la enseñanza magisterial, de la interpretación auténtica de la fe que confirma, corrige y encauza las interpretaciones personales. La tarea de descubrir la significación teológica de los acontecimientos se enriquece cuando es asumida por todos, laicos y pastores, varones y mujeres, teólogos "de a pie" y teólogos profesionales, y es fruto de un esfuerzo multidisciplinar capaz de auscultar con mayor rigurosidad los múltiples ángulos y facetas que tiene la realidad.

Es esta riqueza de perspectivas, esta diversidad de experiencias y saberes, estas oposiciones aparentemente contradictorias, las que el Centro Teológico Manuel Larraín quiere aprovechar para interpretar teológicamente el presente, en un tiempo de muchos cambios, en este "tránsito cultural de proporciones" (2).

Se lo hace bajo el impulso extraordinario de un Concilio que ha recuperado para los laicos la importancia que tienen en el Pueblo de Dios. Esta, sin embargo, el mismo Vaticano II la entiende en términos algo dicotómicos, al adjudicar a los laicos la tarea secular de hacerse cargo de lo terrenal, mientras que al clero y a los religiosos correspondería lo espiritual (LG 30 y 36); como si, por otra parte, fuera posible a los bautizados construir la ciudad, formar familias, desarrollar el país, hacer negocios, investigar la naturaleza y, en todo esto, triunfar sobre los poderosos condicionamientos psicológicos y sociológicos que menoscaban su libertad y, con mayor razón, sobre las tentaciones al mal, sin el auxilio del Espíritu de Dios. Estas actividades reconocidamente laicales, el deber de responsabilizarse activamente de la Iglesia y la vocación teológica de la misma atañen a todos los bautizados, pastores y laicos, sin perjuicio de los ministerios y especializaciones que facilitan una mejor organización de la misión evangelizadora.

(2) Conferencia Episcopal de Chile, En camino hacia el Bicentenario de la Independencia Nacional, $\mathrm{N}^{\circ} 6$, año 2004 . 
De acuerdo al espíritu dialogal del Concilio Vaticano II, el Centro Teológico Manuel Larraín pretende nutrir su investigación y reflexión de la conversación que el centro abre y estimula entre creyentes cuya vocación teológica reconoce a todos por igual. Cuenta con la orientación de los pastores y de teólogos profesionales. Y, de un modo novedoso, cree en el enriquecimiento que puede significar para la teología tomar en serio el sensus fidelium del pueblo de Dios creyente y teólogo, representado por laicos y laicas que además de su experiencia de padres y madres cristianos, han adquirido la óptica de una disciplina científica o profesional. Su intuición estriba en que el sentido-razón de los acontecimientos que constituyen auténticos signos de los tiempos se captará mejor si el contacto con la realidad se obtiene del sentido-sensibilidad de los cristianos y del sentido-orientación que dan a sus vidas. La sabiduría para orientar cristianamente la vida, el Espíritu la otorga a todos los fieles. La teología profesional necesita más que nunca recuperar la sabiduría espiritual de los teólogos "de a pie". Descartar esta posibilidad, por el contrario, representa una verdadera amenaza para la teología como peligroso es también para las demás ciencias perder el norte de su investigación y defender su campo con un lenguaje críptico.

\section{PRINCIPIOS DE DISCERNIMIENTO}

El discurso teológico sobre el presente histórico es posible cuando tomamos en serio que la vocación teológica es cosa de todos los bautizados y cuando nos disponemos a integrar el aporte de todas las ciencias. Pero, ¿cómo articula una teología de los signos de los tiempos la visión de fe con la mirada que le ofrecen las ciencias y la experiencia en general?

Hasta aquí sabemos, al menos, que un discurso teológico del presente no se estructura a partir de "principios teológicos" que se aplican ni en base a "datos científicos" que se aceptan acríticamente, sino a través de la articulación dialéctica entre las explicaciones científicas y la comprensión teológica. Solo así la teología puede superar la yuxtaposición de afirmaciones que opera sobre una división de la verdad en dos planos incomunicados. No hay dos accesos a la realidad alternativos, la fe y la razón. La unidad de la verdad, en palabras de Fides et Ratio, urge a encontrar la fe en la razón y a esta en aquella.

Una segunda pregunta hace aún más compleja la tarea. ¿Cómo es posible superar la ambigüedad inherente a los signos de los tiempos de poder ser obra de Dios o acciones "diabólicas"? Los acontecimientos humanos, a través de los cuales se expresa la intención histórica de Dios que buscamos, son irremediablemente impuros, ambivalentes, equívocos. Para que el discernimiento de estos signos sea posible se requiere elucidar criterios o principios que sirvan, por un parte, para empalmar el discurso de la fe y el discurso de las ciencias y, a la vez, para distinguir las acciones auténticamente espirituales, las acciones suscitadas por el Espíritu, de las motivadas por otros espíritus (3).

(3) Cf. Pedro Trigo, "El discernimiento de la acción del espíritu en la historia", ITER No 33 (2004) 39-75; Juan Noemi, "La contemporaneidad de la teología. El ejemplo de Paul Tillich", Teología y Vida 17 (1976) 96-97. 
Para los cristianos, el criterio por excelencia de lo que se entiende por Dios, por hombre y por mundo, es Jesucristo, su persona y el advenimiento escatológico de su reino. El depósito de la fe que la Iglesia, a través de sucesivas interpretaciones y actualizaciones, pasa de una generación acerca del significado de Cristo es, por lo mismo, rico e inagotable. A efectos de formular los criterios que nos permiten discernir hoy la acción de Dios en nuestra historia, estos debieran expresarse en términos que la razón científica y la experiencia contemporáneas puedan comprenderlos. Habrá que ser conscientes, empero, que ellos no expresarán definitivamente el significado de Cristo y tampoco impedirá que otras elucidaciones de patrones de juicio sean mejores.

Con todo, en virtud de la fe en el Hijo de Dios es posible deducir dos criterios principales para reconocer la acción de Dios en las acciones humanas. Estos son la libertad y la fraternidad. La confesión de Jesucristo como Hijo de Dios tiene para los cristianos el efecto inmediato de revelarles su propia identidad de "hijos e hijas" de Dios, libres de toda esclavitud y hermanos en principio en una misma familia humana. Proclamando a Cristo como Hijo la Iglesia primitiva salvaguardó esta experiencia extraordinaria de libertad y de solidaridad fraternal, principios de aquella nueva comunidad que la Iglesia una representa en la historia.

En esta fragua epistemológica la Iglesia forjó el concepto de "persona" como su mejor contribución conceptual a Occidente. Al provenir de las explicaciones cristológicas y trinitarias, la aplicación del término "persona" a los seres humanos supone que estos tienen una dignidad irrepetible y una vocación a la comunión; una libertad de señores sobre el mal y un llamado a hacerse siervos por amor unos de los otros.

La persona humana, como el Hijo, es única, capaz de responder por sus actos, merecedora de máximo respeto, protagonista de su vida y dotada de conciencia. En una palabra, la persona es libre. Se constituye en libertad en la medida que, en su interrelación con las otras personas, distingue la verdad de la mentira y del error, y la practica.

La persona humana, en virtud del Hijo, no es persona sin las demás personas. El ser humano progresa como tal en la medida que otros lo reciben en la existencia e interactúan con él a lo largo de la vida. El aislamiento, la marginación y la exclusión frustran la personalidad. La injusticia y el individualismo contemporáneos representan por lo mismo señales inequívocas de involución histórica. Y, por el contrario, nada verifica mejor una nueva humanidad que la opción por los pobres que supera las divisiones con que se aseguran privilegios y reconcilia la familia humana rehabilitando a las víctimas. La libertad es para la comunicación. Allí donde las personas se tratan como "hermanas", cuando cede el miedo a los demás y el afán de prosperar sobre ellos a la fuerza, nace y encuentra su realización la libertad auténtica.

En palabras de Raúl González "a esa interdependencia libre de personas libres la llamamos amor o amistad en sus formas más profundas de implicación personal, justicia en sus formas impersonales de realización social, búsqueda del bien común si la pensamos como tarea de la acción colectiva, solidaridad cuando sigue los impulsos de la compasión y la simpatía por el otro, y la llamaremos propiamente 
fraternidad el día en que seamos por fin capaces de reconocernos unos a otros en el mismo Padre" (4).

El pensamiento cristiano y lo mejor de otras tradiciones seculares proponen la existencia de no contradicción, sino al revés, "la mutua implicación, entre la libertad de las personas y los grupos sociales, y su articulación en estructuras sociales cada vez más fraternas e interdependientes" (5). Una interpretación teológica del presente se hace a la vez describiendo los fenómenos históricos y las experiencias subjetivas, comprendiendo la significación que ellos tienen en referencia a la presencia de más o menos libertad y fraternidad, y valorándolo todo a la luz de la Palabra divina.

A modo de inspiración recordamos a Mons. Larraín cuando, a propósito del Concilio Vaticano II, nos dice: "Lo que nosotros hemos vivido es impresionante, pero si en América Latina no ponemos atención a nuestros propios signos de los tiempos, el Concilio pasará al lado de nuestra Iglesia, ¿y quién dice lo que sucederá después?" (6). También el padre Hurtado, en el primer editorial de Mensaje, apuntaba a la necesidad de captar la acción profunda de Dios en la historia presente: "Y sin embargo, en medio de todas esas angustias de nuestro mundo, hay un Mensaje de verdad y de vida que puede devolverle la tranquilidad y la paz. Nuestros contemporáneos dan la triste impresión de peregrinos que cruzan un desierto, muriendo de sed, y sin saberlo están pasando por sobre ríos subterráneos: con solo cavar un poco, tendrían fuentes de aguas vivas que saltan hasta la vida eterna" (7).

\section{RESUMEN}

Este texto hace las veces de carta de navegación del Centro Teológico Manuel Larraín. Ha sido escrito con la colaboración de todos sus miembros, para iluminar la actividad del centro. En él se describe el intento de discernir los "signos de los tiempos" actuales, cumplido en cuatro grupos que a lo largo de un año y medio se han reunido para discutir sobre cuatro temas especialmente relevantes. Este documento quiere ser teología de una acción que, en este caso, ha consistido fundamentalmente en una conversación libre, informada y multidisciplinar entre hombres y mujeres de fe.

\section{ABSTRACT}

This text serves as a navigation chart for the "Centro Teológico Manuel Larraín" (Manuel Larraín Theological Center). It has been written with the collaboration of all of its members, in order to enlighten the activity of the center. In it, the attempt to discern the current "signs of the times" is described, an attempt engaged in by four groups which have met in the course of a year and a half to discuss four especially relevant themes. This document has the intention of being theology of an action that, in this case, has consisted fundamentally in a free, informed and multidisciplinary conversation among men and women of faith.

(4) Raúl González, "Variables en el discernimiento histórico", ITER No 33 (2004) 10-11.

(5) Raúl González, o.c., 10-11.

(6) Citado por Martín Maier, "L'Amérique Latine”, en Joseph Doré, Le devenir de la théologie catholique mondiale depuis Vatican II, Beauchesne, Paris, 2000, p. 343.

(7) Revista Mensaje, Vol. I, N ${ }^{\circ} 1$, p. 1. 